\title{
CONSTRUINDO CORPOS NAS CONSULTAS MÉDICAS: Uma etnografia sobre Hipertensão Arterial em Salvador, Bahia
}

\author{
Elena Calvo-Gonzalez*
}

\begin{abstract}
Através da análise etnográfica da aplicação da tecnologia de medição da pressão arterial nas consultas médicas em um centro médico público na cidade de Salvador, proponho pensar a articulação do processo de objetificação do corpo com o universo da experiência, tanto de médicos quanto de pacientes. Atentarei para a maneira como os atores envolvidos aplicam no encontro clínico conhecimentos provindos do cotidiano e do âmbito da Biomedicina, sinalizando como o controle da Hipertensão é produzido por, e por sua vez produz, corpos que vivenciam o mundo através de matrizes diferenciadoras tais como classe, gênero ou raça. Estes corpos e estas matrizes de significação não podem ser separados, no seu sentido real, material, do seu sentido simbólico e figurado.

PALAVRAS-CHAVE: raça, corporificação, tecnologia, hipertensão, etnografia.
\end{abstract}

O paciente, a pedido do médico, senta na maca. O médico se aproxima, carregando em uma mão o estetoscópio e na outra o esfigmomanômetro. Pendura o estetoscópio no pescoço, enquanto pergunta ao paciente: “Tem tirado a pressão?” O paciente olha para o médico, nega com a cabeça e estende o braço direito, sem o médico pedir. O médico coloca o manguito do esfigmomanômetro no braço estendido do paciente e o insufla, enquanto ajeita o estetoscópio nos ouvidos e no braço do paciente. O paciente começa a falar: "É porque...". O médico, com um gesto com a mão, pede silêncio ao paciente. Ele olha para o braço, enquanto o médico olha para o ponteiro do esfigmomanômetro. O medico esvazia o manguito e anuncia o valor da pressão: "18 por 10”. "Doutor, tá boa?” “Tá não, tá é alta! Tem que tomar seu remédio. Já tomou hoje?” (Diário de Campo, 28/07/08)

Durante o meu trabalho de campo ${ }^{1}$ em uma instituição pública de saúde que cuida de pacientes com hipertensão em Salvador, presenci-

* Doutora em Antropologia Social. Professora Adjunta da Universidade Federal da Bahia.

Faculdade de Filosofia e Ciências Humanas. Estrada de São Lázaro, 197. Cep: 40210-000. Federação - Salvador Bahia - Brasil. elenasemaga@gmail.com

${ }^{1}$ Para manter o anonimato dos atores envolvidos na minha pesquisa, não identificarei o posto de saúde onde fiz pesquisa de campo, situado em uma região central da cidade, tampouco os médicos (ambos na casa dos 50 anos, de classe média e não-negros) e pacientes junto aos quais fiz pesquisa. aria encontros parecidos com o descrito acima em todas as consultas médicas. A medição da pressão arterial, junto com os dados do histórico do paciente contidos no prontuário, é o que designa os pacientes, na visão clínica, como hipertensos ou normotensos, controlados ou não. Já na classificação cotidiana e informal dos médicos, eles são marcados como aderentes (ao tratamento) ou rebeldes, difíceis de tratar ou, retrospectivamente, da raça negra. Por outro lado, a medição da pressão, como explicarei neste artigo, se faz também presente na experiência dos pacientes de serem hipertensos, porém não necessariamente compartilhando a centralidade que tem no encontro clínico. A análise poderia se deter nesse processo de transformação, durante a aplicação da medição da pressão arterial, do corpo como objeto a ser medido, classificado, monitorado e controlado (Souza, 2005), e do lugar dessa objetificação na experiência relatada de viver com hipertensão (Peres et al., 2003; Machado; Car, 2007). No entanto, gostaria de ampliar as possibilidades de análise do lugar que a medição de pressão arterial tem para pensar a articulação desse processo de objetificação do cor- 
po com o mundo da experiência, tanto de médicos quanto de pacientes. Terei como pano de fundo da minha análise a abordagem de Mol \& Law (2004) sobre "produção" (enactment) de corpos, assim como o conceito teórico de corporificação (ou corporeidade) de Csordas (1994), que incorpora elementos da fenomenologia e da análise de Bourdieu sobre a relação entre estrutura social e habitus dos indivíduos. Essas duas abordagens teóricas permitirão me focar na maneira como os atores envolvidos aplicam, no encontro clínico, conhecimentos provindos tanto do cotidiano quanto do âmbito da biomedicina. Mostrarei como o processo de diagnóstico e controle da hipertensão é "produzido" por, e por sua vez “produz”, corpos que vivenciam o mundo através de matrizes diferenciadoras, tais como classe, gênero ou raça, ${ }^{2}$ corpos e matrizes de significação da experiência que não podem ser separados, no seu sentido real, material, do seu sentido simbólico e figurado.

Para empreender essa tarefa, dividirei o artigo em três seções: em primeiro lugar, gostaria de introduzir, de uma maneira muito abreviada, o surgimento do corpo moderno como objeto do olhar biomédico, localizando a hipertensão historicamente como resultado do que Foucault denominou de "novo modo de conhecimento". Na segunda seção, apresento etnograficamente como a hipertensão é “produzida” no encontro clínico. Mostro o envolvimento dos médicos e pacientes no processo de "objetificação" do corpo e a inserção desse processo dentro duma experiência vivida, assim como se apresento noções de diferença de classe na relação entre médico e paciente. Na terceira parte do artigo, focarei especificamente a maneira como a categoria raça é envolvida nesse "fazer" hipertensão. Apresentarei dados etnográficos assim como discursos mais amplos da literatura médica nacional e internacional ou ideias circulantes sobre raça no Brasil, tendo como objetivo contribuir para a análise do papel do cotidiano das instituições de saúde nos processos de racialização.

Essas matrizes de diferenciação, por sua vez, estão permeadas por relações de poder e resistência que, por motivos de espaço, não serão objeto específico de análise neste artigo.

\section{CORPO OBJETO E CORPO SUJEITO: do nascimento da clínica à hipertensão como doença}

A passagem para a doença ser considerada resultado da expressão de lesões celulares no lugar de ser tida como fenômeno vital é resultado da consolidação do padrão analíticomecanicista da biomedicina, processo cujo início é datado do século XVIII, passando a consolidar-se no século XIX (Camargo, 2005). O corpo moderno, objeto de intervenções médicas, tem como característica se estender em dimensões de espaço e tempo: é um espaço anatômico, um conjunto de órgãos inter-relacionados, porém dissolvidos pela prática da patofisiologia. Por outro lado, é estendido no tempo, pois a emergência desse novo corpo dependeu da emergência de novas maneiras de conhecimento, de um novo "modo de olhar" (Foucault, 1976). Tal mudança envolveu todo um "dispositivo", ou aparelho sociomaterial, sem o qual esse novo modo de conhecer não seria possível. Dentro desse "dispositivo" encontraríamos a reorganização da profissão e o treinamento médico, além da transformação da clínica em lugar de estudo, onde os pacientes são posicionados e tidos como objeto desse novo modo de olhar. O surgimento de novas técnicas investigativas, tais como o estetoscópio, não é considerado por Foucault como consequência dessa mudança epistemológica, senão como elementos constitutivos dela. Central seria também a passagem para uma concepção do corpo e da doença como processos e não como estruturas. Essa passagem pode ser identificada na crescente importância da fisiologia, em que os eventos são organizados através do tempo, em comparação com a velha ênfase da anatomia na composição espacial dos corpos. ${ }^{3}$ Para Foucault, a aplicação de tecnologias biomédicas, incluindo, dentre

Assim, por exemplo, em exames post-mortem como a autopsia, realizada no final do século XVII no cadáver do médico fisiologista Marcello Malpighi, era identificada tanto a hipertrofia do ventrículo esquerdo quanto a presença de hemorragia cerebral, dois fenômenos que, hoje em dia, são considerados como consequência de quadros hipertensivos, mas que, à época, não eram explicáveis pelo modelo anatômico (Fleming, 1997, p.180). 
elas, o acompanhamento da evolução do paciente mediante prontuário médico, estaria inserida dentro do processo de objetificação do corpo como fim da análise e da intervenção da biomedicina.

Nesse sentido, podemos vincular o surgimento da hipertensão como achado médico ao desenvolvimento de tecnologias médicas como a uroanálise e o uso do esfigmomanômetro. Esse último seria desenvolvido, quase em sua forma atual - com manguito que infla e coluna de mercúrio-, no final do século XIX pelo italiano Scipione RivaRocci (Roguin, 2005). A adição da técnica auscultatória para determinar a pressão sistólica e diastólica seria estabelecida por Korotkoff no começo do século XX. Por outro lado, o desenvolvimento do prontuário individual centrado no histórico de cada paciente, também datado do começo do século XX (Berg; Harterink, 2004, p. 26), permitiria traçar a trajetória das medições de pressão arterial em cada indivíduo. Isso levaria a achados patológicos, tanto individuais quanto populacionais, que elevariam a hipertensão à condição de "anormalidade". Apesar de essa "anormalidade” ter sido estabelecida, não era, porém, incorporada à rotina das consultas médicas, pois não existiam medicamentos anti-hipertensivos que controlassem os níveis pressóricos de uma maneira satisfatória e (ou) sem provocar sérios efeitos colaterais que levassem à cessação da terapia. A dieta Kempner, que restringia o tipo de alimento a ser ingerido a arroz fervido sem sal e frutas, popularizada no começo da década de 40 do século XX como tratamento da hipertensão, não conseguia reduzir os níveis de pressão de maneira significante. Significante, porém, era o aborrecimento que essa restrição alimentar provocava nos pacientes. Esse quadro mudaria com a introdução, no ano de 1957, do diurético clorotiazida, ainda hoje em dia empregado na terapêutica antihipertensiva (Esunge, 1991, p. 621).

O sucesso da clorotiazida levou ao incremento da pesquisa por anti-hipertensivos eficazes e toleráveis pelos pacientes, especialmente levando em conta que a maioria dos indivíduos diagnosticados com hipertensão teriam essa como condição "silenciosa" (assintomática). O desenvolvi- mento de remédios toleráveis abriria uma nova época de prática médica. Antes da chegada de remédios anti-hipertensivos seguros e toleráveis, os pacientes tomavam remédios somente quando tinham mal-estar. Os medicamentos antihipertensivos modificaram esse panorama, e indivíduos sem sintomas passaram a ter prescritos remédios para prevenir os efeitos da hipertensão nos seus órgãos. Essas pessoas incorporariam ao seu cotidiano um regime terapêutico de controle da pressão arterial. ${ }^{4}$ A ênfase mudou do tratamento de lesões à sua prevenção.

Por outro lado, a aplicação da tecnologia da medição da pressão arterial é dependente do uso do equipamento adequado e do envolvimento do corpo do médico através dos seus sentidos. ${ }^{5}$ Assim, engaja-se a audição para detectar os sons de Korotkoff, que indicam pressão sistólica e diastólica, e a visão para confirmar no ponteiro do esfigmomanômetro a cifra de pressão medida em miligramas de mercúrio. Esse envolvimento do corpo do médico tem se tornado um ponto polêmico na literatura e na clínica da hipertensão (Hartland, 1996; Mion Jr. et al., 1996). No primeiro dia do meu trabalho de campo, por exemplo, um dos médicos do posto de saúde onde fiz a pesquisa, ao saber o foco de meu estudo, fez a observação de que: " $50 \%$ das medições de pressão que temos não são confiáveis. Você vai ver, desde a posição da pessoa que mede a pressão à posição do manguito, tem tanta coisa que não se faz como deveria ser!” (Diário de Campo, 04/07/08).

Apesar de considerar a contribuição de Foucault importante para a compreensão da objetificação do corpo pela biomedicina, localizando-a dentro de um processo discursivo mais

${ }^{4}$ A medicina preventiva tem avançado crucialmente com o crescente desenvolvimento e aperfeiçoamento da tecnologia médica, como as histórias dos exemplos da detecção de genes ou marcadores séricos ligados a doenças como o câncer de mama ou de próstata nos mostram (Oliffe; Thorne, 2007; Gibbon, 2006).

${ }^{5} \mathrm{O}$ aprendizado dessa técnica configura-se como experiência incorporada, dependente da apropriação do reconhecimento de certos sons e sua aplicação prática. As possibilidades corpóreas dos médicos, por exemplo, em relação ao seu sentido da audição, são, assim, "feitas" através desse aprendizado e a cada aplicação da medição da pressão, que depende crucialmente do engajamento do corpo do médico (Rice; Coltart, 2006). 
amplo de normatização da existência humana e do controle e administração de certos grupos sociais, alinho-me com autores que atentam para a contribuição que uma abordagem etnográfica pode ter para enriquecer a compreensão da biomedicina e de seu lugar no mundo contemporâneo. Acredito que a análise do encontro clínico pode esclarecer não somente os modos como os sujeitos se apropriam, negociam e transformam as práticas e discursos hegemônicos da biomedicina (Lupton, 1997, p.95). Pode também resgatar a centralidade da experiência corporificada, indo para além da divisão mecanicista ebipolar entre sujeito e objeto.

O corpo ocupa um lugar essencial no processo que Mol \& Law chamam de "fazer" a doença (Mol; Law, 2004). No caso da hipertensão, e como já indica a fala do médico acima citada sobre a sua importância na aplicação da medição da pressão arterial, esse lugar é central, de uma maneira tanto histórica quanto na prática clínica. A hipertensão, como condição médica, depende do estabelecimento de um elo entre um corpo ideal e um corpo desviante ou hipertenso. Essa conexão é feita através da correlação estatística entre certas medidas de pressão arterial e o surgimento de patologias, como acidente vascular cerebral ou falha renal. Por sua vez, o processo de aplicação da tecnologia da medição da pressão, durante a consulta médica, feito "corretamente" ou "como não se deveria fazer", depende também da relação entre dois corpos presentes no encontro clínico. Por outro lado, a tecnologia da medição da pressão coloca o paciente em relação com outros corpos, tanto apresentados na consulta como objetos a serem medidos ou sujeitos a habitar esses corpos-objetos. Esses corpos estão permeados por matrizes de significação social da experiência, e são (re)criados em cada encontro clínico. Dito isso, antes de passar para a análise da (re)criação de corpos no encontro entre médico e paciente,vejamos primeiro como é definida a hipertensão como categoria da biomedicina.

\section{"COISAS QUE NÃO SE FAZEM COMO DEVE- RIA SER": hipertensão arterial}

Para um paciente adulto ser enquadrado dentro da categoria "hipertenso", seus níveis de pressão arterial devem ter sido identificados no consultório como fora do padrão "normal", definido pela Sociedade Brasileira de Hipertensão nas suas V Diretrizes Brasileiras sobre Hipertensão como "140/90 (sistólica e diastólica) mmHg" (Sociedade Brasileira de Hipertensão, 2006).

Ao mesmo tempo em que essa definição localiza a hipertensão no "corpo-objeto", submetido à medição da pressão arterial, nas mesmas diretrizes encontramos a presença do "corposujeito", implícita na compreensão dos fatores de risco para o desenvolvimento de hipertensão arterial. Assim, fatores socioeconômicos, sal, obesidade, álcool e sedentarismo são mencionados como relacionados ao surgimento de hipertensão nos indivíduos. Na argumentação da Sociedade Brasileira de Hipertensão, na menção a como os corpos tornam-se hipertensos através de certos comportamentos, esses fatores são relacionados tanto a uma escolha individual quanto a um fator populacional e social. Por um lado, menciona-se a informação de que "indivíduos sedentários apresentam risco aproximado $30 \%$ maior de desenvolver hipertensão que os ativos" (Sociedade Brasileira de Hipertensão, 2006, p. 31). Por outro lado, o consumo de sal é apresentado em relação a “... populações com alta ingestão de sal [...]. Entre os índios Yanomami, que têm baixa ingestão de sal, não foram observados casos de hipertensão arterial". Ao mesmo tempo, argumenta-se que, “... em população urbana brasileira, foi identificada maior ingestão de sal nos níveis socioeconômicos mais baixos", juntamente com a "ingestão de álcool, índice de massa corpórea aumentado, estresse psicossocial, menor acesso aos cuidados de saúde e nível educacional”, tidos como fatores associados para a maior prevalência de hipertensão arterial em estratos socioeconômicos mais baixos. As escolhas dietéticas ou de hábitos de vida dos indivíduos 
são apresentadas como (parcialmente) relacionadas a situações estruturais, as quais, por sua vez, se incorporam e se apresentam sob outras feições ou hábitos nos corpos pertencentes a esses grupos. Essa concepção é muito parecida com a encontrada na literatura das ciências sociais sobre corporificação.

As diretrizes da Sociedade Brasileira de Hipertensão, apesar de definirem o que é hipertensão e apontarem para fatores de risco para seu desenvolvimento ou prevalência populacional, não nos ajudam a desvelar a maneira como se dá, na prática, a articulação entre a noção de corpo como objeto mensurável e como sujeito (subjetividade). Para esse fim, passemos à análise dos dados de campo.

\section{"CORPOS" EM PROCESSO: hipertensão na consulta médica}

A paciente, uma mulher de média idade, argumenta que, quando "sente a sua pressão", sente uma "agonia". "A pressão não se sente", responde o médico, enquanto realiza a medição da pressão arterial. "18 por 9, sua pressão é alta assim e está tomando remédio? Tem quanto tempo que não está tomando remédio?”. A paciente olha para o médico. "É que quando eu sinto a pressão alta que tomo remédio, que sinto aquele negócio (faz um gesto com as mãos levando-as para a nuca), que a pressão está alta eu tomo”. O médico retorna à mesa e questiona a paciente: "E como a Sra. sabe (que a pressão está alta), é adivinha?”. Ela nega com a cabeça e argumenta que “... várias vezes que eu senti isso tirei a pressão e estava alta!”. O médico olha para o prontuário. "E a pressão da Sra. está alta assim porque ela é alta, ou porque não toma remédio? Nunca vai poder responder, se é alta porque não tomou o remédio ou é que o remédio não está controlando. Eu também não vou poder responder, e não vou poder modificar sua medicação, entendeu?" (Diário de Campo, $31 / 07 / 08)$.

Somente é possível falar de uma pressão arterial de "18 por 9" se o esfigmomanômetro é colocado no braço do paciente, é insuflado, o corpo do médico através do sentido da audição é engajado, conseguindo identificar quando as batidas do pulso surgem e somem, e o sentido da visão engajado no ponteiro do esfigmomanômetro, identificando quando a agulha faz uma breve parada assim como o valor que marca. Nesse processo, o "corpo como sujeito" dá lugar à centralidade do corpo como objeto a ser medido, representado em duas cifras. Se focarmos somente o resultado dessas cifras, ofusca-se tanto o processo vivido, através do qual o médico incorpora durante seu treinamento a técnica de medição da pressão, para ser capaz de realizar o procedimento posteriormente, quanto a experiência e a vivência do paciente. A preeminência do corpo-objeto na leitura feita pelo médico através do esfigmomanômetro se reflete na argumentação de a “pressão não se sentir”. Essa argumentação pode ser encaixada dentro do processo de afirmação de autoridade do médico na relação médico-paciente como possuidor da verdade sobre o corpo-objeto, à qual o médico apela no citado trecho (Souza, 2007). Porém, o corpo experienciado não é completamente deixado de lado. A experiência de sentir mal-estar ainda está presente no discurso dessa paciente, por exemplo, quando argumenta tomar remédio somente quando "sente" sua pressão alta, e não de uma maneira contínua, como indicado pelo médico. A maneira de tomar remédio também pode se argumentar que esteja associada ao "estoque de conhecimento" dos pacientes da clínica - em sua quase totalidade pertencentes às camadas populares sobre como lidar com doenças: toma-se remédio quando se está doente, parando quando se está saudável. Por outro lado, há certa tentativa por parte da paciente de aproximar a experiência do corpo vivido ao corpo objetificado através da realização da medição arterial sempre que sentia a pressão alta. A experiência do próprio corpo é confirmada pelos valores da medição da pressão nessas ocasiões. Dessa maneira, a hipertensão torna-se um processo que modifica tanto a maneira de entender o próprio corpo quanto a significância atribuída às percepções sentidas em comparação com as medições "objetivas" da biomedicina, em processos que podem mudar durante a trajetória do indivíduo como hipertenso. Alguns pacientes que já têm vários anos de tratamento, de fato, anunciam, durante a consulta, antes da medição, uma estimativa de como 
estão os valores da pressão arterial, mostrando estranheza quando as cifras anunciadas pelo médico não correspondem aos valores por eles esperados.

As modificações dessas percepções e o que elas significam para a rotina e os corpos dos hipertensos têm sido amplamente discutidos pela literatura em relação à dificuldade de adesão ao tratamento medicamentoso da hipertensão (Cade, 1997; Nobre, 2001; Castro; Rolim, 2006). Ter de lidar com efeitos colaterais, com a necessidade de procurar remédios no posto de saúde, ou, em certas ocasiões, conseguir o dinheiro para poder comprá-los na farmácia, ou ainda a dificuldade de lembrar os diferentes horários nos quais há de se tomar as medicações são ajustes ao cotidiano que se apresentam normalmente relatados pelos pacientes no contexto da consulta médica. A própria consulta médica, por sua vez, implica um ajuste no cotidiano do paciente hipertenso:

Entra na consulta uma senhora de meia idade junto com outra mulher mais nova. As duas se sentam. O médico olha o prontuário da paciente, a mulher mais velha, e pergunta pelos remédios que está tomando. A acompanhante começa a falar, mas o médico se dirige à paciente e pergunta se está sentindo alguma coisa. ”Doutor, eu fico às vezes assim, com dor de cabeça”. O médico pergunta se sente tosse, a paciente nega. $\mathrm{O}$ médico solicita à paciente se sentar na maca para proceder à medição da pressão arterial. A paciente se dirige à maca, senta-se e imediatamente estica o braço esquerdo. O médico mede a pressão arterial da paciente e anuncia em voz alta o valor "15 por 10. Tem certeza que está tomando todos os remédios que estão na sua receita?”. A paciente olha para o chão e admite não ter tomado um deles hoje de manhã "É que, Doutor, tenho de pegar ônibus, na correria, para chegar aqui, e se tomar esse aí, me urino toda e não dá para acontecer isso no ônibus, né?". O médico retira o esfigmomanômetro do braço da paciente e retorna à mesa, enquanto argumenta com a paciente "E se não tomar e tiver um derrame no ônibus, como vão ficar as coisas?" (Diário de Campo $12 / 08 / 08)$

No discurso do médico, o descumprimento do regime medicamentoso pelo paciente é tido como mostra da não-adesão, nem que seja em uma dose, às prescrições médicas. Essa não-adesão, como veremos, está frequentemente relacionada pelo médico à posição de classe dos pacientes. A rejei- ção ao tratamento também está presente na ideia de os pacientes “não aceitarem” sua identificação como hipertensos:

A acompanhante do paciente, um homem idoso, relata ser ele portador da doença de Chagas e ter tido um Acidente Vascular Cerebral bastante recente. "Ele não acreditava que era doente, não tomava o remédio... Tomava, mas não como toma agora". O médico responde dizendo que "O que ele teve (AVC) não foi por causa da doença do barbeiro, foi por causa da hipertensão. Colesterol alto e pressão mal cuidada”. A acompanhante vira para o paciente e em voz baixa diz: "Agora você vai ter que comer sem sal!” (Diário de Campo, $14 / 08 / 08)$.

No caso desses pacientes, a experiência de "se sentir bem", do corpo experienciado, é negada pela leitura dos seus corpos através da medição da pressão arterial, criando um descompasso entre corpo-objeto e corpo-vivido, o que leva a muitos deles a privilegiarem a experiência vivida de não ter mal-estar e a negar a sua condição de doentes, o que provavelmente influencia na rejeição ao tratamento.

Por outro lado, aqueles pacientes que aceitam se submeter à rotina de controle biomédico da hipertensão terão seu cotidiano afetado pela necessidade das visitas frequentes à clínica para o controle periódico dos níveis de pressão arterial. A necessidade de manter essa rotina de visitas é enfatizada pelos profissionais médicos como parte do tratamento. Assim, terão de comparecer para confirmar o diagnóstico de hipertensão, como nos casos em que é indicada a Medição Residencial da Pressão Arterial (MRPA), ou a Medição Ambulatória da Pressão Arterial (MAPA) (Sociedade Brasileira de Hipertensão, 2006), e (ou) para monitorar os efeitos da medicação antihipertensiva. A inclusão de novos remédios no regime medicamentoso dos pacientes precisa de um cuidado maior no começo, pois é possível se apresentarem casos de hipotensão, acarretando possíveis problemas aos pacientes, como, por exemplo, desmaios. A pergunta “Tomou a pressão ultimamente?” ou “Tem tomado a pressão?” é rotineiramente feita durante as consultas, tanto daqueles pacientes que são considerados como "controlados" quanto daqueles cujos níveis pressóricos são tidos como “oscilantes”. 
A ida frequente ao posto de saúde para que seja realizada a medição de pressão, ou, no caso dos pacientes com melhores condições econômicas, a compra de monitores automáticos, é incentivada tanto pelos médicos quanto pelas enfermeiras do posto. Esse incentivo se apresenta, por exemplo, nos comentários positivos dirigidos aos pacientes que chegam na consulta com o cartão para anotar as medições de pressão arterial, fornecido pelo posto, preenchido com anotações estruturadas e frequentes. Os pacientes, com a aplicação repetida da medição da pressão arterial e seu registro nesses cartões, passam a incorporar a ideia de controle da pressão através dessas tecnologias, dentro do processo de objetificação mencionado anteriormente.

Ao mesmo tempo, esse corpo-objeto revela fronteiras permeáveis, sendo afetado também pelo seu entorno. A permeabilidade desse corpo se apresenta de uma maneira clara na descrição da chamada "hipertensão do avental branco", em que os valores da medição realizada pelo médico são superiores aos realizados por outro profissional (por exemplo enfermeiras) ou pelo próprio paciente em casa, e são considerados efeito da presença do médico na medição da pressão, criando ansiedade no paciente, o que leva a esse aumento (Mion Jr. et al., 1996). Alguns pacientes podem ter consciência dessa permeabilidade, da influência da presença do médico em outro corpo-vivido, incorporando, dentro de uma apropriação mais ampla dos discursos e práticas da biomedicina, o discurso da literatura médica sobre a "hipertensão do avental branco" às suas próprias explicações sobre o que se passa com os seus corpos.

O médico pergunta à paciente se ela é hipertensa, o que é negado por ela. O médico questiona se, pelo fato da paciente ser obesa, "Vai que tem hipertensão e não sabe”. A paciente argumenta que, sendo que seu marido é hipertenso, ela costuma acompanhá-lo ao posto para medir a pressão dele e costuma medir a pressão dela também. O médico mede a pressão da paciente e anuncia o valor: "13 por 9". A paciente argumenta que "Está assim por causa desse jaleco”. O médico a alerta: "Pode ser, mas cuidado, pode subir mais do que isso." (Diário de Campo 27/08/2008).
O corpo-experienciado tem também um lugar central no controle dos efeitos colaterais da terapia anti-hipertensiva, como tosse ou mal-estar geral, além de, em ocasiões, sentir os seus efeitos na forma de episódios de hipotensão, ou, no caso de alguns pacientes, de serem capazes de "sentir" a subida de pressão através da associação de alguns sintomas, como dores de cabeça ou pressão na área posterior da cabeça, com a presença de níveis de pressão arterial excepcionalmente altos.

A escolha do ajuste dos remédios prescritos aos pacientes une os corpos presentes na consulta com outros corpos envolvidos no desenvolvimento e testagem de medicações antihipertensivas. No desenvolvimento e marketing de remédios para a hipertensão, os ensaios clínicos randomizados se tornaram o campo de batalha entre medicações desenvolvidas por diferentes laboratórios farmacêuticos. As diferenças estatísticas entre os efeitos desses remédios, assim como os seus efeitos colaterais, traduzem-se em um cenário no qual os discursos sobre as vantagens de um remédio sobre outro, baseados em agregados estatísticos, se incorporam através da literatura científica à qual os médicos têm acesso, assim como dos visitadores médicos enviados pelos laboratórios farmacêuticos para promover os produtos da companhia. Ao mesmo tempo, os discursos sobre a efetividade dos diferentes fármacos se adicionam, na prática clínica da hipertensão no sistema de saúde pública brasileira, aos discursos sobre custos dos administradores desse sistema, que financia a compra dos remédios antihipertensivos a serem distribuídos na rede pública de saúde (Mion Jr. et al., 2006).

Por outro lado, a maneira como os pacientes lidam com os efeitos colaterais das medicações, ou, em geral, com a toma de medicação, por vezes não cumprindo total ou parcialmente o regime medicamentoso prescrito, é relacionada pelo médico ao "problema social" que existe na Bahia:

Você viu: esse paciente, na idade dele, não tem ninguém que o acompanhe, não consegue ler, é analfabeto... Você acha que esse paciente consegue tomar a medicação? Não consegue... Não con- 
segue. Ninguém me convence de que consegue. Se você for ver, aqui na Bahia, o problema social é muito maior do que o problema médico... Vem da cultura dos escravos, dos índios e dos portugueses burros que vieram ao Brasil! (Diário de Campo 19/08/08).

Assim, o efeito que o social tem nos corpos não é somente, como apontado pelas Diretrizes da Sociedade Brasileira de Hipertensão, torná-los “doentes", passíveis de sofrer as consequências fisiológicas, a longo prazo, da presença consistente de níveis de pressão arterial elevados. Para o médico, problema médico são os níveis de pressão apresentados pelos indivíduos, ou seja, a leitura do corpo-objeto pela técnica da medição da pressão arterial, e a sua subsequente redução através da adesão ao tratamento medicamentoso proposto pela biomedicina. ${ }^{6}$ Já o "problema social” é o efeito que as relações sociais, na sua forma de habitus de classe, tem nas pessoas, tornando-as inaptas (ou indispostas) a se submeterem às prescrições médicas. Esse efeito pode estar relacionado tanto a questões estruturais, que impossibilitariam o acesso a remédios que não sejam fornecidos pelo sistema público de saúde, quanto do conhecimento próprio às classes populares, as quais priorizam tratamentos alternativos ao prescrito pelo médico:

Olhando para o prontuário do paciente, o médico pergunta se a pressão está controlada. "É que... De uns tempos para cá, deu isso, a pressão alta. Mas eu tomo remédio de berinjela, de maracujá, de chuchu". O médico pergunta se também toma a medicação. "Direto não, porque a pressão está controlada; tomo assim, umas duas vezes por semana”. Após a medição da pressão, o médico anuncia o valor: "18 por 10. Sua pressão está alta, está tomando o remédio desse jeito à toa. Vai ter que tomar remédio. Tome sua berinjela e laranja como suco, e não como remédio. Não se engane não, vou mandar engarrafar tudo e vou ficar rico! Tem tanto paciente meu que quando morrer vai ter um pé de berinjela na barriga, de tanto caroço de tanta berinjela!” (Diário de Campo 21/08/08)

Sobre a preferência dos médicos pela terapia medicamentosa em relação a outras terapias, tais como prescrição de dieta e exercícios, e a relação dessa preferência ao controle do conhecimento e estabelecimento da autoridade médica, ver Camargo (2005).
No entanto, a esse mesmo corpo-sujeito, considerado pelo médico como lócus de costumes e crenças ligadas à sua posição de classe que dificultam o tratamento, é exigido, além do cumprimento das prescrições médicas de remédios e mudanças de hábitos, a incorporação de (parte) do conhecimento técnico sobre essas prescrições:

O médico reclama com o paciente que este não sabe quais remédios toma. "Se for parar na emergência, a primeira coisa que vão perguntar para você é o que toma, e aí não vai saber dizer, vai ficar difícil.” (Diário de Campo 22/07/08)

Porém nem todos os pacientes que apresentam problemas em aderir ao tratamento proposto são lidos pelo médico como resultantes de "problemas sociais":

Paciente, mulher, meia idade. Chega à consulta trajando roupas bastante elegantes e entra cumprimentando o médico de uma maneira muito confiante. Durante o relato da paciente, que reclama do alto custo das medicações prescritas para ela no médico do plano de saúde que costumava frequentar, o médico a interrompe argumentando: "Mas a sua pressão é difícil de controlar, precisa dessas medicações, vai fazer o quê? Eu posso passar esses remédios que tem aqui no posto, mas não vai adiantar nada; se o outro médico passou os outros remédios é porque a senhora precisa deles, vai ter que tomar eles". A paciente pergunta ao médico se ele sabe quanto é a aposentadoria de servidor público. O médico, visivelmente irritado, responde afirmativamente, inclusive relembrando à paciente que ele mesmo “... é servidor público, assim como a senhora já foi”. A paciente argumenta que, então, deve entender que, com a aposentadoria, não tem condições de pagar 200 reais por mês em remédios. O médico preenche uma nova receita, a paciente agradece ao médico a emissão da receita e sai da consulta (Diário de Campo 16/09/2008).

A expectativa do médico - baseada na similaridade do habitus de classe, de compartilhar com a paciente a importância dada à aderência ao tratamento proposto, e conseguir arcar com o custo econômico - o leva a desestimar o apelo à falta de condições econômicas para pagar os remédios prescritos, e a enfatizar a necessidade individual de tratamentos pautada pelo desenvolvimento da doença na paciente. A experiência incorporada de classe, que influencia tanto médicos quanto 
pacientes, torna-se assim um dos eixos de significação do encontro clínico. No entanto, é importante frisar que o isolamento e a identificação de classe como categoria que influência a experiência vivida dos atores envolvidos é um artifício analítico. No mundo vivido, ela se dá em conjunção com outros eixos de significação, tais como idade, aparência, beleza, origem, ou raça. Apesar desses e de outros possíveis fatores estarem presentes de uma forma ou outra na consulta, há algumas categorias, como raça, que se apresentam com mais relevância, seja pela importância na biomedicina, de uma maneira histórica ou contemporânea, ou no cotidiano, na configuração das ideias sobre diferença no Brasil.

Antes de entrar na discussão etnográfica sobre a presença da categoria raça no encontro clínico, e sendo que dentro da literatura Biomédica há uma longa e polêmica história de associação entre raça e doença, ${ }^{7}$ torna-se necessário analisar primeiro a produção discursiva sobre raça e Hipertensão. Avaliarei posteriormente a interação desses discursos provindos do âmbito Biomédico com outros discursos circulantes sobre raça.

\section{RAÇA E HIPERTENSÃO: uma relação polêmica}

Na publicação Cadernos de Atenção Básica: Hipertensão Arterial Sistêmica, do Ministério da Saúde, o apartado "Hipertensão em Populações Especiais" começa com o verbete "Negros e miscigenados", no qual se adverte que:

Nos negros, a prevalência e a gravidade da hipertensão são maiores, o que pode estar relacionado a fatores étnicos e/ou socioeconômicos. Em nosso país predominam os miscigenados, que

${ }^{7}$ A literatura sobre raça e doença é extensa e especializada, compreendendo áreas de estudo tão diversas quanto a História, os Estudos Culturais, as Ciências Sociais, alem de, é claro, da biomedicina e áreas afins, tais como a genética. De uma maneira geral, dentro dos textos da biomedicina que fazem menção a essa categoria, podemos dividi-los entre aqueles que fazem uso da categoria raça de uma maneira não-refletida, e aqueles que se debruçam de forma crítica, seja para defender o abolir seu uso, sobre essa categoria (ver Tishkoff; Kidd, 2004; Pena, 2005; Ossorio; Duster, 2005; Sinha et al., 2006; Frank, 2007; Rosenberg et al., 2002; Risch, 2000). podem diferir dos negros quanto às características da hipertensão. Não há evidências de ação diferenciada das drogas anti-hipertensivas em nossa população. Entretanto, estudos recentes em populações de indivíduos negros norte-americanos, os usos de iECA se mostraram menos eficazes, especialmente na prevenção de AVC, que outras classes de anti-hipertensivos. Devendo, portanto, não serem considerados de primeira escolha nesta população (Brasil. Ministério da Saúde, 2004, p.34).

A relação entre raça e hipertensão tem sido objeto de inúmeras pesquisas tanto epidemiológicas quanto clínicas. A prevalência epidemiológica maior de hipertensão entre negros norte-americanos, nos Estados Unidos, e negros e miscigenados, no Brasil, aludida no texto acima citado, tem dado lugar a diversos modelos explicatórios para essa ocorrência, que podem ser classificados em três grupos:

1. Ênfase na presença de taxas maiores de comportamentos de risco nessas populações. Essa ênfase pode ser mais centrada nos comportamentos individuais, ou acompanhada por uma explicação social mais ampla do porquê desses comportamentos.

2. Centrados na genética, tendo como base da hipótese a origem africana comum dentre estes grupos e as condições históricas do sistema colonial escravagista, que levariam a diferenças evolutivas (por exemplo, na hipótese de que a maior retenção de sal seria vantajosa frente a uma situação adversa, como a escravidão, especialmente na travessia atlântica, dando lugar a uma seleção natural desses indivíduos) (Barreto, 1993). O grande questionamento em relação a essa hipótese se dá em estudos comparativos da prevalência de hipertensão arterial essencial em populações do mundo. Esses estudos mostram que não há uma correlação direta entre populações classificadas como negras (como, por exemplo, em países como a Nigéria) e altas taxas de hipertensão arterial, existindo, porém, uma correlação entre processos de urbanização e incremento das taxas de hipertensão arterial, o que desestabiliza a hipótese unicamente genética (Cooper et al., 2005).

3. Argumentos que combinam os fatores sociais 
com biológicos, incluindo uma ideia mais abrangente de sociedade e cultura. As taxas de prevalência mais altas nessas populações são vistas como expressões biológicas de racismo, como, por exemplo, através do stress devido às privações econômicas e à resistência à opressão racial, levando a hábitos nocivos, como dietas inadequadas e maiores taxas de consumo de álcool e tabaco (Krieger, 2000; Brondolo et al., 2004). Destaca-se também, ampliando essa perspectiva para além das críticas lançadas, por considerar os grupos sociais como homogêneos (Almeida Filho, 2004, p.868), o estudo de Dressler e Santos (2000), no qual os autores testam a hipótese da relevância da "consonância cultural", isto é, a maneira "como os indivíduos são capazes de aproximar seus próprios comportamentos aos modelos culturais de vida que são compartilhados pela comunidade”. Quanto maior a consonância cultural do indivíduo, menor será sua pressão arterial. A vantagem dessa abordagem é que combina os aspectos individuais com os societários, abrindo espaço para a heterogeneidade dentro dos grupos, assim como incorporando um conceito de "cultura" mais processual do que atrelado a uma ideia fixa e reificada de cultura.

É claro que esses modelos podem ser combinados e usados ao mesmo tempo. Assim, por sua disseminação (e.g. ATarde 26/4/2007).

O epidemiologista Josué Laguardia critica o uso de modelos explicatórios para a hipertensão apoiados nas descobertas da nova genética, que baseiam suas análises em grupos raciais. Segundo Laguardia, esses estudos se distanciam das abordagens holísticas do sujeito como socialmente contextualizado, e apontam para uma abordagem instrumentalizada do indivíduo, aumentando, assim, o essencialismo e o determinismo genético, a visão das raças como verdades biológicas, e ocultando a variabilidade genética dentro dos grupos ditos raciais, a-não rigidez das fronteiras entre grupos e os processos sócio-históricos de criação de identidades raciais (2005).

Por outro lado, essas críticas não têm sido freio para o desenvolvimento de discursos que, baseados na análise genômica de marcadores de ancestralidade, argumentam que a autoatribuição racial de um indivíduo é um bom marcador de ancestralidade genômica, e, portanto, o conceito deveria ser mantido na medicina (Risch, 2000). Nessa mesma linha de argumentação, foi aprovado em 2005, nos Estados Unidos - apesar de questionamentos sobre como isto fomentaria a crença na existência de "raças" biologicamente diferentes, assim como dúvidas em relação aos interesses farmacêuticos envolvidos -, o fármaco Bi-Dil, o primeiro tratamento para insuficiência cardíaca específico para "afro-americanos" (Sankar; Kahn, 2005). No Brasil, na bula do medicamento antihipertensivo Cozaar ${ }^{\circledR}$ (assim como de algumas versões genéricas da Losartana potássica, substância ativa desse medicamento), há uma referência aos seus benefícios "na morbidade e mortalidade cardiovascular comparados aos do atenolol, que não se aplicam a pacientes negros com hipertensão e hipertrofia ventricular esquerda". O geneticista Sergio Pena questiona o uso da categoria raciais como fator relevante na escolha de remédio para tratar cada paciente. Para Pena, esse uso desconsidera o fato de as raças estarem baseadas em diferenças externas icônicas que, mesmo correlacionando-se com o continente de origem, não refletem variações genômicas generalizadas 
entre grupos. As categorias raciais estariam vinculadas tanto a variações locais no uso de nomenclaturas de classificação, quanto a processos históricos ligados a essas variações locais (2005, p. 330). No caso do Brasil, e devido à história de miscigenação, estudos genômicos sobre ancestralidade indicam que a aparência externa não é necessariamente um bom indicador de ancestralidade genômica individual (Pena et al., 2000; Parra et al., 2003). No entanto, é bom relembrar o já citado Caderno de Atenção Básica do Ministério da Saúde, no qual, mesmo apontando para a prevalência dos miscigenados no país, e não estando ciente de existir uma diferença entre eles e os negros em relação às características da HAS nem à resposta fisiológica a fármacos, não se hesita em desaconselhar o uso de um fármaco para essa população, com base em estudos com "negros norteamericanos". ${ }^{8}$ Deixando de lado questionamentos em relação à origem e à validez ou não dessa abordagem médica racializada, a questão, apontada pelo antropólogo Peter Wade é indagar de que maneira os processos através dos quais as realidades sociais, que são as raças, apesar de não constituírem uma realidade biológica têm um certo envolvimento com a biologia pelo fato de serem realidades corporificadas. Ou seja, parte do apelo continuado do conceito de raça é pelo fato de ser associado ao campo da biologia e da natureza através, por exemplo, da percepção das diferenças de fenótipos ou sua hereditabilidade. Como realidade corporificada, a raça torna-se parte dos processos que "fazem" corpos (Wade, 2004, p.164-165). O encontro clínico torna-se, como veremos na próxima seção, um dos lócus nos quais essa realidade corporificada surge, junto a ideias circulantes tanto no meio médico quanto na sociedade em geral, sobre a natureza da raça no Brasil.

${ }^{8}$ Para Chor Maio e Monteiro, textos como esse seriam exemplo da racialização crescente do campo da saúde no Brasil. Para esses autores, a emergência do campo da "Saúde da População Negra” na formulação e implantação de políticas públicas está relacionada, entre outros fatores, ao surgimento de um feminismo negro brasileiro nos debates sobre saúde reprodutiva, movimento influenciado pela militância negra feminista norte-americana e apoiado economicamente por fundações filantrópicas norte-americanas, assim como à apropriação seletiva de uma literatura acadêmica produzida em países anglo-saxões (2005, p.423-424).

\section{“FAZENDO” HIPERTENSÃO ATRAVÉS DE CATEGORIAS RACIAIS; "FAZENDO" RAÇA ATRAVÉS DA HIPERTENSÃO}

A representante comercial de um laboratório farmacêutico entra na consulta e oferece ao médico, além de várias caixas de amostras grátis de diversos remédios, um exemplar da revista Pesquisa Médica, que o médico subsequentemente me entrega enquanto conversa com ela. Folheio o exemplar e encontro um artigo sobre "Farmacogenética: o futuro da prescrição médica”. Ao lado da discussão sobre a polêmica em torno da aprovação do BiDil® nos Estados Unidos como medicamento "étnico", o texto da revista menciona como a bula da Losartana indica que esse medicamentote "não se aplica a pacientes negros”. Quando a representante do laboratório vai embora, pergunto ao médico sobre essa menção na bula. "Na verdade, está escrito errado. Não é que não deva se prescrever a negros. É que não adianta prescrever, pois não vai fazer nada, não vai resolver... Mas se usa em casos de hipertensão que não são graves; agora, tem mais chance em negro de não controlar". Pergunto ao médico o porquê disso. ‘É porque a literatura confirma, aqui no nordeste, que a população é de maioria negra... É mais difícil de controlar a hipertensão. Eles tem bons dentes, bons corpos, mas a pressão é difícil de controlar”. (Diário de Campo 28/08/2008).

Após essa conversa com o médico, ele passou a me apontar, no caso de alguns pacientes, como a hipertensão era difícil de controlar "por causa da raça”. Inevitavelmente, os pacientes que o médico apontava, que tinham a raça como fator dominante para a dificuldade do controle, eram de pele muito escura, os chamados localmente de pretos:

Aí é que a experiência conta: a raça. Toma três medicações e não controla a pressão. Aí não adianta incluir Losartana. Tem que aumentar a dose e adicionar outro remédio. (Diário de Campo 21/ 08/2008).

Perguntei ao médico em relação àqueles que tinham a pele mais clara, mas que, mesmo assim, não eram considerados brancos, os localmente chamados de morenos. ${ }^{9}$

${ }^{9}$ Apesar de o termo moreno também poder ser empregado para denominar pessoas de cor escura, dentro de um uso do termo racial denominado pela antropóloga Robin Sheriff de "pragmático" (Sheriff, 2001). 
... pode ter, pode ter porque já carrega o gene... Mas quanto mais pretos mais difícil de controlar, em termos de grupo, claro, em termos estatísticos". Pergunto em relação aos pacientes brancos. "Nos brancos não é tão grave, nos descendentes de espanhol, de português, mas você vê que aqui na Bahia não tem branco [...] já vem a mistura (Diário de Campo 21/08/2008)

Assim, ao mesmo tempo em que o médico incorpora os discursos sobre hipertensão arterial em negros, é influenciado pelas ideias tanto de pureza racial branca quanto discursos sobre a natureza miscigenada da população brasileira. Há, em jogo, uma identificação dupla, na qual, mesmo deixando a dúvida da herança africana pairar na população brasileira como um todo, somente aqueles de aparência de pele mais escura são identificados como negros, leitura feita somente a partir da aparência externa. Apesar de admitir que aqueles com pele menos escura (ou, inclusive, pele considerada branca) podem carregar os genes do controle difícil da hipertensão, todos os exemplos que o médico se referiu como evidência durante as consultas eram indivíduos muito escuros. Em uma ocasião, o médico se referiu a como

... os portugueses trouxeram dois tipos de escravos ao Brasil: os bantus e os nagôs. Os nagôs eram mais altos, os bantus mais baixinhos, mais gordinhos. E você vê, quase todos os negros que têm hipertensão difícil de controlar eram altos, já percebeu? É isso... Só que depois houve toda essa mistura e aí a amostragem fica difícil de controlar, né? (Diário de Campo 23/08/2008)

O conceito de pureza negra, correlacionado à presença de uma aparência tida como mais africana (pele muito escura, cabelo crespo) está presente nesses discursos que associam hipertensão e raça. ${ }^{10}$ Apesar de apontar que os morenos (oficialmente denominados de pardos pelo IBGE) poderiam ter o gene que faz a hipertensão difícil de controlar, não são esses os exemplos que o médico

${ }^{10}$ A descrição dos nagôs em termos físicos mais positivos (note-se o diminutivo que o médico emprega para descrever as qualidades físicas dos bantus) pode ser associada um imaginário, já presente nos escritos do século XIX do médico baiano Raymundo Nina Rodrigues, que situavam culturalmente os nagôs enquanto superiores aos bantus (Nina Rodrigues, 1933). me apontava durante as consultas, mencionando somente a "raça" do paciente como fator influente no controle da hipertensão de certos (não todos) indivíduos que tinham a pele muito escura.

Argumento, por conseguinte, que a maneira como a raça se apresenta no consultório em relação aos corpos hipertensos é mais a criação de um elo (retórico) entre certos corpos presentes na consulta (no caso, o de pacientes de pele muito escura) e outros corpos do passado do Brasil, como a menção aos bantus e os nagôs reforça. Esse elo retórico é também feito a partir da equivalência entre categorias locais de classificação racial e de outros lugares presentes na literatura acadêmica médica. O termo negro, por exemplo, que, nos Estados Unidos, englobaria todos os descendentes de africanos, seguindo a regra da hipodescendência, independentemente da aparência externa, na Bahia (e, em geral, no Brasil) não é necessariamente aplicado a todos aqueles que apresentam alguma marca fenotípica africana, sendo possível encontrar indivíduos considerados brancos, na Bahia, que seriam classificados como negros nos Estados Unidos. Tal e como vimos nas notas de campo, os pacientes identificados como negros pelo médico eram aqueles que apresentavam um fenótipo tido como mais africano, mais negro, deixando fora desse grupo os pacientes com aparência mais clara e mestiça.

Os conceitos de pureza, tanto branca quanto negra perpassam a maneira como o argumento sobre a relação entre raça e hipertensão é explicado pelo médico, apresentando-se mais como um raciocínio a posteriori do que um fator tido como relevante no diagnóstico e prescrição de medicação de pacientes. Apesar de argumentar que "não adianta prescrever Losartana a negros", durante minha pesquisa presenciaria esse mesmo médico prescrevendo esse remédio a pacientes que tinham pele bastante escura. Da mesma maneira, presenciaria outros casos nos quais a "leitura" do corpo do paciente por parte do médico privilegiava outros indicadores que não a raça. Exemplo disso foi o caso de uma paciente jovem, de pele muito escura, que, apesar de apresentar níveis altos de pressão arterial, difíceis de controlar com a medicação 
prescrita, não levou o médico a usar o argumento racial para tentar entender o porquê desses altos valores de pressão arterial. Devido à idade da paciente, suspeitou ser um caso de hipertensão arterial como consequência de algum outro problema de saúde mais sério, respondendo negativamente a minha pergunta sobre se a raça seria um fator relevante nesse caso.

Ao mesmo tempo em que se poderia argumentar que o conceito de raça invocado $-a$ posteriori pelo médico mobiliza ideias sobre as supostas características biológicas inatas de certos indivíduos, em outras encontros clínicos, o conceito de raça empregado está mais relacionado a processos que, ao mesmo tempo em que “emergem” do corpo, têm-no como alvo final:

A paciente, de meia idade e obesa, senta na maca enquanto aguarda o médico fazer a medição da pressão arterial. O médico se aproxima da maca, olha para a paciente e comenta como, no caso de uma obesidade como a dela, é possível a indicação de cirurgia bariátrica. O rosto da paciente mostra surpresa e medo: "Doutor, eu tenho é ossos grandes, minha filha não é gorda, nem meu filho". O médico procede à medição da pressão: “17 por 10”. 'Doutor, tá boa?' O médico nega com a cabeça, ao que a paciente responde "Mas tem estado baixa! É porque o Senhor falou em cirurgia, aí... Fiquei nervosa”. O médico aguarda uns minutos para proceder à segunda medição da pressão, e conversa sobre a possibilidade de a paciente se submeter à cirurgia. "É porque já é da constituição da Senhora, é da raça. Sua filha ainda não é gorda porque essa nova geração tem muito mais esporte, a alimentação é outra... Mas se tem a tendência, vai eventualmente ficar, vai. A Senhora é descendente de italianos e de espanhóis, das duas raças da Europa que mais gostam de comer. Só faltou um pouco de português e de grego, essa galera gosta de comer!” (Diário de Campo 21/08/2008).

Vemos, assim, que as noções de raça mobilizadas não se restringem a uma concepção biogenética de herança de caracteres biológicos. A noção de raça - como grupo de herança tanto biológica quanto comportamental - que notamos no trecho citado acima, quando o médico fala tanto da "tendência" à obesidade quanto do gosto cultural pela mesa farta, nos alerta para a maneira como essa categoria se apresenta imbricada com outras noções sobre diferença, sejam elas conceitualizadas nas categorias analíticas de classe ou cultura. Dessa maneira, devemos estar atentos ao modo como julgamentos sobre comportamento e costumes estão atrelados a concepções essencializadas da diferença, identificando a presença de discursos que ligam o âmbito da natureza ao âmbito dos comportamentos, ou, empregando o termo antropológico, à cultura (Wade, 2010).

\section{CONCLUSÃO}

A necessidade de refletir etnograficamente sobre as práticas da biomedicina como campo formador de concepções sobre a existência humana tem tido um espaço cada vez mais relevante nas Ciências Sociais contemporâneas. A análise do papel que a tecnologia médica ${ }^{11}$ tem nos processo de objetificação do corpo, assim como a resistência a esses processos, é um dos campos de análise frutíferos desses estudos. No entanto, como defendo neste artigo, essas reflexões podem ser enriquecidas se atentarmos para a presença da experiência e do modo de vida cotidiano dos atores envolvidos nas interações que se dão por intermédio da biomedicina. Nas consultas médicas, podemos encontrar a presença dos discursos e práticas da biomedicina, assim como as experiências e trajetórias de vida de médicos e pacientes. Ambos reconhecem no outro as marcas de diferenciação corporificadas, que estruturam as interações sociais tanto dentro do consultório quanto fora. Por outro lado, no encontro clínico. não estão presentes somente os corpos dos médicos e dos pacientes. Os discursos da biomedicina trazem ao encontro clínico outros corpos não-presentes no consultório, por exemplo, a partir da própria definição

${ }^{11}$ Em sua maioria, o foco nos estudos antropológicos sobre o impacto da biotecnologia na criação de novas formas de sociabilidade se centra em tecnologias mais novas, como, por exemplo, as tecnologias reprodutivas (Laqueur, 2000; Franklin, 1995), da nova genética (Nelkin, 1996; Finkler, 2000), ou tecnologias de imagem (Simon, 1999; Taylor, 2000; Kaufman; Morgan, 2005; Chazan, 2008). Porém não devemos perder de vista como a popularização de certas tecnologias mais antigas, que são aplicadas de maneira cada vez mais rotineira, tais como a medição da pressão arterial ou dos níveis de glicose, também tem um impacto, pelo fato de serem tecnologias baratas e de aplicação em massa. 
de algumas doenças, como a hipertensão, baseada numa possibilidade estatística. As expectativas em relação ao que pode se esperar do outro estão permeadas por experiências prévias que vão constituindo os corpos como pertencentes a determinadas categorias. A classe ou a raça se fazem presentes no encontro clínico tanto na literatura biomédica estudada pelo médico quanto em noções mais amplas que afetam tanto a sua interpretação dessa literatura quanto a própria experiência no mundo, seja do paciente ou do médico. As experiências prévias dos médicos em relação ao modo como os pacientes lidam com a sua condição, seus habitus de classe e o que esperar e poder cobrar dos pacientes se apresentam nas suas interações com eles. Da mesma maneira, experiências prévias dos pacientes com instituições médicas levam a certa expectativa em torno da consulta e quanto ao que pode se esperar do médico. E, no entanto, apesar de a consulta seguir um roteiro médico, nem o médico nem o paciente serão sempre os mesmos nessa interação, nem literal nem figuradamente, no sentido das experiências de ambos estarem a todo tempo sendo reconfiguradas com o passar da vida. A vida não segue um roteiro. Nessas interações durante os encontros clínicos, tanto médico quanto paciente vão tendo seu corpo (re) construído, incorporando experiências antigas às interações novas, que ambos levarão para além dos muros do posto de saúde.

(Recebido para publicação em novembro de 2010) (Aceito em fevereiro de 2011)

\section{REFERÊNCIAS}

ALMEIDA FILHO, Naomar. Modelos de determinação social das doenças crônicas não transmissíveis. Ciência \& Saú de Coletiva, Rio de Janeiro, v.9, n.4, p.866-884, 2004.

BARRETO, Ney Dilson Magalhães et al. Prevalência da hipertensão arterial nos indivíduos de raça negra. Arquivos Brasileiros de Medicina, Belo Horizonte, v.67, n.6 p.449-451, 1993.

BERG, Marc; HARTERINK, Paul. Embodying the patient: records and Bodies in Early 20th-century US Medical Practice. Body \& Society, [S.1.], n.10, p.13-41, 2004.

BRASIL. Ministério da Saúde. Cadernos de Atenção Básica: hipertensão arterial sistêmica, 2004. Disponível em: www.materiasespeciais.com.br/saude/hipertensao.jpg > Acesso em: 20 maio 2007.
BRONDOLO, Elizabeth et al. Perceived racism and blood pressure: a review of the literature and conceptual and methodological critique. Annals of Behavioral Medicine, Boston, v.25, p.1, p.55-65, 2005.

CADE, Nágela Valadão. O cotidiano e a adesäo ao tratamento da hipertensão arterial. Cogitare Enfermagem Florianópolis, UFPr, v.2, n.2, p.10-15, jul./dez., 1997.

CAMARGO, Kenneth R. de. A biomedicina. PHYSIS: revista Saúde Coletiva, Rio de Janeiro, v.15, Supl., p.177-201, 2005.

CASTRO, Maria Euridéia de; ROLIM, Maysa Oliveira.Conhecimento e estereótipo de trabalhadores acerca da hipertensão. Escola Anna Nery: revista de Enfermagem, Rio de Janeiro, v.10, n.2, ago., p.235-240, 2006.

COOPER, Richard S. et al. An international comparative study of blood pressure in populations of European vs. African descent BMCMedicine, 2005, 3:2. Disponível em: www.biomedcentral.com/ 1741-7015/3/2. Acesso em: 23 jun. 2008.

CSORDAS, Thomas. The body as representation and being in the world. In: . Embodiment and experience: the existential ground of culture and self. Cambridge: Cambridge University Press, 1994.

CHAZAN, Lilian Krakowski. 'É... tá grávida mesmo! E ele é lindo! A construção de 'verdades' na ultra-sonografia obstétrica. Historia, Ciência, Saúde-Manguinhos, Rio de Janeiro FGV, v.15, n.1, p.99-116, 2008.

DRESSLER, William W.; SANTOS, José Ernesto dos. Social and cultural dimensions of hypertension in Brazil: a review. Cadernos Saúde Pública, Rio de Janeiro, v.16, n.2, abr./jun., p.310-315, 2000.

ESUNGE P M. From blood pressure to hypertension: the history of research. Journal of the Royal Society of Medicine, London, v. 84, n.10, p.621, 1991.

FLEMING, Peter R. A short history of cardiology. Amsterdam; Atlanta, GA: Rodopi. 1997.

FINKLER, Kaja. Experiencing the new genetics: family and kinship on the medical frontier. Philadelphia: University of Pennsylvania Press. 2000.

FONSECA DA CRUZ, Isabel Cristina; LIMA, Robéria de. Etnia Negra: um estudo sobre a hipertensão arterial essencial (HAE) e os fatores de risco cardiovasculares. 1999. Disponível em: www.uff.br/nepae/detecnegro.doc 1999.

FOUCAULT, Michel. The birth of the clinic: an archaeology of medical perception. New York: Vintage Books, 1976.

FRANK, Reanne. What to make of it? The (re)emergence of a biological conceptualization of race in health disparities research. Social Science $\mathcal{E}$ Medicine, [S.l.], v.64, n.10, p.1977-1983, 2007.

FRANKLIN, Sarah. Postmodern procreation: a cultural Account of assisted reproduction. In: GINSBURG, Faye D.; RAPP, Rayna. Conceiving the new world order: the global politics of reproduction. Berkeley: University of California Press, 1995.

GIBBON, Sahra. Nurturing women and the BRCA Genes: gender, activism and the paradox of health awareness. Anthropology \& Medicine, Baltimore, USA, v.13, n.2, p.57171(15), aug., 2006.

HARTLAND, Joanne. Automating blood pressure measurements: the division of labour and the transformation of method. Social Studies of Science, New York, SAGE, v.26, n.1, p.71-94, feb., 1996.

KAUFMAN, Sharon R.; MORGAN, Lynn M. The anthropology of the beginnings and ends of life. Annual Review of Anthropology, Santa Cruz, USA, v.34, p.317-341, 2005.

KRIEGER, Nancy. Discrimination and health. In: BERKMAN, L.; KAWACHI, I. (Ed.) Social epidemiology. 
Oxford: Oxford University Press, 2000.

LAGUARDIA, Josué. Raça, genética e hipertensão: nova genética ou velha eugenia? História, Ciências, SaúdeManguinhos, Rio de Janeiro, v.12, n.2, p.371-393, maio/ ago., 2005 .

LAQUEUR, Thomas. From generation to generation: imagining connectedness in the age of reproductive technologies. In: BRODWIN, Paul E. (Ed.) Biotechnology and culture: bodies, anxieties, ethics. Bloomington University of Indiana Press, 2000.

LUPTON, Deborah. Foucault and the medicalisation critique. In: BUNTON, Robin (Org.) Foucault, health and medicine. London: Routledge, 1997. p.94-110.

MACHADO,Leise Rodrigues Carrijo; CAR, Marcia Regina. Dialética do modo de vida de portadores de hipertensão arterial: o objetivo e subjetivo. Revista Escola Enfermagem USP, São Paulo, v.41, n.4, 2007. Disponível em: www.scielo.br/scielo.php?Script $=$ sciarttext\&pid $=$ S0080-62342007000400006\&lng=en\&nrm=isso. Acesso em: 13 set. 2008.

MAIO, Marcos Chor; MONTEIRO, Simone. Tempos de racialização: o caso da 'saúde da população negra' no Brasil. História, Ciências, Saúde-Manguinhos, Rio de Janeiro, v.12, n.2. p.419-446, maio/ago., 2005.

MION JR. D.; SILVA, GV; ORTEGA K.C.; NOBRE F. A importância da medicação anti-hipertensiva na adesão ao tratamento. Revista Brasileria de Hipertensão, Ribeirão Preto,SP v.13, n.1, p.55-58, 2006.

MOL, AnneMarie; LAW, John. Embodied action, enacted bodies: the example of Hypoglycaemia, Body \& Society, [S.I.] v.10, n.2-3, p.43-62, 2004.

NELKIN, Dorothy. The social dynamics of genetic testing: the case of fragile-X. Medical Anthropology Quarterly, [S.l.], v.10, n.4, p.537-550, dec., 1996.

NINA RODRIGUES, Raymundo. Os africanos no Brasil. São Paulo: Ed. Nacional, [1933], 1988.

NOBRE, Fernando. Adesão ao tratamento: o grande desafio da hipertensão. São Paulo: Lemos Editorial. 2001.

OLIFFE, John; THORNE, Sally. Men, masculinities, and prostate cancer: australian and canadian patient perspectives of communication with male physicians. Qualitative Health Research, Salt Lake City, USA, v.17, n.2, p.149-161, 2007.

OSSORIO, P.; DUSTER, T. Race and genetics: controversies in biomedical, Behavioral, and Forensic Sciences. American Psychologist, Washington,DC, v.60, n.1, p.115, 2005.

PARRA, Flavia C. et al. Color and genomic ancestry of brazilians. Proceedings of the National Academy of Sciences of USA, Washington, DC, v.100, n.1, p.177-182. 2003.

PENA, Sérgio Danilo. Retrato molecular do Brasil. Ciência Hoje, São Paulo, v.159, p.16-25, 2000.
. Razões para banir o conceito "raça" da medicina brasileira. História, Ciências, Saúde-Manguinhos, Rio de Janeiro, v.12, n.2, p.321-346, maio/ago., 2005.

PERES, Denise S; MAGNA, Jocelí Mara; VIANA, Luis Atílio. Portador de hipertensão arterial: atitudes, crenças, percepções, pensamentos e práticas. Revista de Saúde Públi$c a$, Rio de Janeiro, v.37, n.5, p.635-642, 2003.

RICE, Tom; COLTART, John. Getting a sense of listening: an anthropological perspective on auscultation. British Journal of Cardiology, London, v.13, p.56-57, 2006.

RISCH, Neal. Searching for genetic determinants in the new millennium. Nature, Stanford, CA, n.405, p.847, 2000 .

ROGUIN, Ariel. Scipione Riva-Rocci and the men behind the mercury sphygmomanometer. International Journal Clinical Practice, Haifa, Israel, v.60, n.1, p.73-79, jan., 2006.

ROSENBERG, Noah A. et al. Genetic structure of human populations. Science, Ohio,USA, v.298, p.2381-2385, dec., 2002.

SANKAR, P.; KAHN, J. BiDil: race medicine or race marketing?. Health Affairs, Betheda,MD,USA, n.24, p.54555463. 2005.

SHERIFF, Robin. Dreaming equality: color, race and racism in urban Brazil. Camden, NJ,USA: Rutgers University Press, 2001.

SIMON, Christian M. Images and image: technology and the social politics of revealing disorder in a North American Hospital. Medical Anthropology Quarterly, Bristol, v.13, n.2, p.141-162, june, 1999.

SINHA, M. M. et al. Self-reported race and genetic admixture. New England Journal of Medicine, Bristol, p.354421, 2006.

SOCIEDADE BRASILEIRA DE HIPERTENSÃO, V Diretrizes Brasileiras de Hipertensão. Disponível em: <http:/ w w w. s b n.o r g. b r / D i r e t r i z e s / V_Diretrizes_Brasileiras_de_Hipertensao_Arterial.pdf $>2006$.

TAYLOR, Janelle S. An all-consuming experience: obstetrical ultrasound and the commodification of pregnancy. In BRODWIN, Paul E. (Ed.) Biotechnology and culture: bodies, anxieties, ethics. Bloomington: University of Indiana Press, 2000.

TISHKOFF S. A.; KIDD K. K. Implications of biogeography of human populations for 'race' and medicine. Nature Genetics, London, v.36, n.11, Suppl, p.S21-S27, nov., 2004

WADE, Peter. Human nature and race. Anthropological Theory, Manchester, USA, University Manchester, v. 4, n.2, p.157-172, 2004

. Presence and absence of race. Patterns of Prejudice, London, v.44, n.1, p.43-60, 2010.

JORNAIS E REVISTAS:

Jornal ATarde (Salvador, Bahia) 


\section{BUILDING BODIES IN MEDICAL CONSULTATIONS: an ethnography of Arteri- al Hypertension in Salvador, Bahia}

\section{Elena Calvo-Gonzalez}

Through ethnographic analysis of the application of technology to measure blood pressure in medical consultations in a public medical center in Salvador, I am proposing to think of the articulation of a process of objectification of the body with the universe of experience, both by doctors and by patients. I will look carefully at the way the actors involved apply knowledge in the clinical encounter stemmed from the daily life and scope of Biomedicine, signaling how the control of hypertension is produced by and in turn produces, bodies experiencing the world through differentiating matrices such as class, gender or race. These bodies and these matrices of significance can not be separated in their real, material, symbolic and figurative sense.

KEYwords: race, embodiment, technology, hypertension, ethnography.

\section{LA CONSTRUCTION DES CORPS DANS LES CONSULTATIONS MÉDICALES: une ethnographie de l'hypertension artérielle à Salvador de Bahia}

Elena Calvo-Gonzalez

Grâce à l'analyse ethnographique de l'application de la technologie des mesures de tension artérielle au cours des consultations médicales, dans un centre de santé publique à Salvador, nous nous proposons de faire le lien entre le processus d'objectivation du corps et l'univers de l'expérience, autant pour les médecins que pour les patients. Nous serons attentifs à la manière dont les acteurs impliqués utilisent leurs connaissances lors de la consultation, connaissances issues de leur quotidien et du domaine de la Biomédecine, afin de montrer comment le contrôle de l'Hypertension est produite par, mais produit à son tour, des corps qui vivent l'expérience du monde à travers des matrices qui établissent des critères de différenciation tels que classe sociale, sexe ou race. Ces corps et ces matrices ne peuvent être séparés, dans leur sens réel, matériel, de leur sens symbolique et figuré.

Mots-CLÉs: race, corporification, technologie, hypertension, ethnographie

Elena Calvo-Gonzalez - Doutora em Antropologia Social. Professora Adjunta da Universidade Federal da Bahia. Tem experiência na área de Antropologia, com ênfase em Antropologia Política, atuando principalmente nos seguintes temas: comunidades e Estado, políticas públicas, identidade e raça. Publicações recentes: CALVO-GONZALEZ, E.; ROCHA, Vera. Está no sangue: a articulação de idéias sobre raça e ancestralidade entre famílias de portadores de doença falciforme em Salvador, Bahia. Revista de Antropologia (USP. Impresso), v. 53, 2010, p. 277-320; CALVO-GONZALEZ, E.; DUCCINI, Luciana. In: Donald V.L. MacLeod; James G. Carrier. (Org.). Tourism, power and culture: anthropological insights. Bristol: Channel View Publications, 2010, p. 134-152; CALVO-GONZALEZ, E. Construindo a comunidade: um assentamento do MST no Nordeste. In: Miguel Carter. (Org.). Combatendo a desigualdade social: o MST e a reforma agrária no Brasil. São Paulo: Editora UNESP, 2010, p. 353-372. 